\title{
ANALISIS FAKTOR YANG MEMPENGARUHI FATIGUE PADA PASIEN KANKER DENGAN KEMOTERAPI : LITERATUR REVIEW
}

\section{[ANALYSIS OF FACTORS AFFECTING FATIGUE IN CANCER PATIENTS WITH CHEMOTHERAPY : LITERATURE REVIEW]}

\author{
Maria Kurni Menga, Elly Lilianty Sjattar, Andi Masyitha Irwan \\ Porgram Studi Magister Ilmu Keperawatan \\ Fakultas Keperawatan, Universitas Hasanuddin, Indonesia \\ Email: mariamenga45@gmail.com \\ DOI : 10.47718/jpd.v8i02.1235
}

\section{ABSTRAK}

Latar Belakang: Kemoterapi merupakan salah satu pengobatan kanker yang memberikan efek samping fatigue yang dapat disebabkan dari berbagai faktor yang dapat berdampak terhadap penurunan kualitas hidup pasien. Tujuan: menganalisa faktor yang mempengaruhi fatigue pada pasien kanker dengan kemoterapi. Metode: Desain penelitian ini adalah tinjauan pustaka. Cari artikel menggunakan database PubMed, Proquest, Ebsco Host dan Science Direct, dengan batasan publikasi artikel selama 5 tahun terakhir (2015-2020), relevan dengan kata kunci pencarian berdasarkan database pada Judul / Abstrak. Ada 5.337 artikel yang ditemukan dan kemudian kami menyaringnya untuk menilai kelayakannya dan mengeluarkan artikel yang tidak memenuhi kriteria inklusi. Sehingga hanya ada 7 artikel yang relevan sebagai referensi utama. Hasil: Diperoleh 7 artikel yang sesuai dengan kriteria inklusi diantaranya 5 artikel merupakan penelitian prospektif dan 2 artikel merupakan penelitian cross-sectional observasional. Ulasan ini ini menyatakan beberapa faktor yang dapat menyebabkan atau memicu fatigue pada pasien kanker dengan kemoterapi yaitu usia, ras, tekanan psikologis, anemia, body mass index (BMI) /Indeks Massa Tubuh, komorbiditas, tingkat fatiguebsebelum kemoterapi. Kesimpulan: Urut perut dan latihan eliminasi layak dijadikan sebagai salah satu intervensi keperawatan untuk menangani masalah konstipasi pada lansia.

Kata Kunci: Pasien kemoterapi, Fatigue. 


\section{ABSTRACT}

Introduction: Chemotherapy was cancer treatment that provides side effects of fatigue which can be caused by various factors that can reduce the patient's quality of life. Aim: The aims of this research was to know effect of uplanasi in Elderly who live in Nursing homes in DKI Jakarta. Method: The design of this study is a literature review. Search for articles using the PubMed, Proquest, Ebsco Host and Science Direct databases, with limited publication of articles for the last 5 years (2015-2020), relevant to search keywords based on the database on Title / Abstract. There were 5,337 articles found and then we screened them to assess their eligibility and excluded those articles that did not meet the inclusion criteria. So that there are only 7 articles that are relevant as the main reference. Results: There were 7 articles that fit the inclusion criteria, of which 5 were prospective studies and 2 articles were cross-sectional observational studies. This review states several factors that can cause or trigger fatigue in cancer patients with chemotherapy, namely age, race, psychological stress, anemia, body mass index (BMI), comorbidity, level of fatigue before chemotherapy. Conclution: Fatigue was a symptom that can affect the quality of life of patients undergoing chemotherapy. This can occur due to several factors that need to be detected early and to the attention of all parties, including patients, families and health workers who treat patients so that they get the right intervention.

\section{Keywords: Chemotherapy Patients, Fatigue}

Kanker merupakan salah satu penyebab utama kematian di

seluruh dunia (Yagli \& Ulger, 2015).Berdasarkan sumber data Global Burden Cancer, International Agency for Research on Cancer (IARC) pada tahun 2018, kematian akibat kasus kanker di dunia sebesar 9,6 juta jiwa, sedangkan jumlah kematian akibat kasus baru kanker terdapat 18,1juta jiwa (Kementerian Kesehatan RI, 2019; Ferlay et al., 2019). Di Indonesia prevalensi penyakit kanker menunjukkan peningkatan dari 1,4 per 1000 penduduk ditahun 2013 menjadi 1,8 per 1000 penduduk pada tahun 2018 
(Kementrian Kesehatan RI, 2018); Kementrian Kesehatan RI, 2015). Dari data tersebut perlu untuk mendapatkan perhatian terhadap penyakit bahkan efek samping terkait pengobatan yang berdampak pada kematian.

Kemoterapi merupakan salah satu pengobatan sistemik yang digunakan untuk memperlambat atau menghentikan pertumbuhan sel-sel kanker yang membelah secara cepat (Robison \& Smith, 2016). Namun, dapat menyebabkan berbagai efek samping dan memberikan gejala yang menyedihkan mulai dari tingkat ringan sampai berat (Lopez et al., 2015;Cleeland et al., 2013).

Efek samping yang dapat muncul pada pasien kanker dengan kemoterapi antara lain fatigue, nyeri, dan mual muntah. (Charalambous \& Kouta, 2016; Galizia et al., 2018; National Cancer Institute, 2018). Namun, fatigue merupakan indikator yang berdampak parah serta mempengaruhi kemampuan fungsional dan kualitas hidup pasien. (Aapro et al., 2016; Schmidt, Wiskemann, Armbrust, et al., 2014). Hal ini dibuktikan bahwa tingkat fatigue yang parah lebih lasim terjadi pada pengobatan kemoterapi (98,30\%) dibandingkan dengan terapi lain seperti radioterapi (45\%)dan merupakan kejadian tertinggi sebesar $(95,8$ \%) (Lopez et al. 2015; Karthikeyan, Jumnani, Prabhu, Manoor, \& Supe, 2012). Selain itu, dalam penelitianYeo \& Cannaday (2015) salah satu dampak terbesar yang dirasakan pasien ketika ditanya efek dari kemoterapi yaitu fatigue dengan tingkat yang bervariasi sekitar $30 \%$ sampai $91 \%$.

keluhan fatigue merupakan gejala yang paling umum dialami pasien kemoterapi dan dapat menyebabkan lebih banyak penderitaan daripada rasa sakit, mual dan muntah. Sehingga, sebagian orang memiliki keinginan untuk menyerah bahkan menghentikan perawatan yang 


\section{METODE PENELITIAN}


tidak relevan, 34 artikel tidak memiliki teks lengkap, danhasil studi yang tidak sesuai 2 artikel. Pada artikel dengan bahasa lain selain bahasa inggris, publikasi ganda dan tidak full taks dikeluarkan.

Setelah penulusuran dari 4 database dan memperoleh 7 artikel yang sesuai dengan kriteria inklusi, 5 artikel merupakan penelitian prospektif (Bischel et al., 2016; Limpawattana et al., 2019; Reinertsen et al., 2017; Vardy et al., 2016; Wright et al., 2015), 2 artikel merupakan penelitian cross-sectional observasional (Araújo et al., 2017; Di Marco et al., 2018). Pada semua studi yang sesuai dengan kriteria inklusi ditemukan ada beberapa faktor yang dapat mepengaruhi atau memperburuk fatigue pada pasien yang menjalani kemoterapi seperti

1. Usia

Dari beberapa artikel yang diulas terdapat 2 artikel yang menemukan bahwa salah satu faktor yang dapat mempengaruhi fatigue pada pasien yang menjalani kemoterapi yaitu usia. Dimana penelitian yang dilakukan oleh Limpawattana et al., 2019 mengatakan usia tua merupakan salah satu faktor independen yang mempengaruhi tingkat fatigue pada pasien yang menjalani kemoterapi, sedangkan penelitian Bischel et al., (2016) juga membuktikan usia memiliki hubungan yang signifikan dengan fatigue $(p<0,001)$, namun fatigue yang dirasakan pasien dengan kemoterapi lebih sering dialami pada pasien usia dewasa muda dibandingkan pada pasien lansia diatas usia $>65$ tahun. 
2. Ras

Ras merupakan faktor yang mempengaruhi dan memperberat fatigue setelah menjani kemoterapi dimana ras berkulit putih dominan mengalami fatigue baik pada pagi maupun malam hari pada pasien yang menerima kemoterapi (Araújo et al., 2017). Serupa dengan penelitian yang mengatakan bahwa kelompok ras berkulit putih selama menerima kemoterapi pada siklus kedua, tingkat keparahan yang dialami baik pada pagi maupun malam hari lebih parah dibandingkan pada ras berkulit hitam setelah menerima kemoterapi (Wright et al., 2015).

\section{Tekanan Psikologis}

Faktor lain yang dapat mempengaruhi fatigue khususnya pada pasien kemoterapi adalah tekanan psikologi, seperti stress, kecemasan dan depresi (Reinertsen et al., 2017; Vardy et al., 2016; Wright et al., 2015b). Fatigue disebabakn oleh tekanan psikologi yang di temukan dalam penelitian Reinertsen et al., (2017) bahwa tekanan psikologi yang ditindak lanjuti selama 2 tahun merupakan satu satunya faktor yang secara signifikan menyebabkan fatigue pada pasien kemoterapi. Serupa dengan penelitian yang mengatakan fatigue memiliki hubungan yang kuat dengan tingkat kecemasan dan depresi yang dialami pada pasien dengan kemoterapi sehingga hal ini jika tidak ditangani kemungkinan besar pasien akan mengalami gejala ini dalam jangka panjang (Vardy et al., 2016). Selain itu, fatigue pada pasien setelah kemoterapi dapat disebabkan akibat tingkat 
keparahan dari gejala depresi yang dialami sebelum menjalani tindakan dan memberikan dampak parah pada keadaan pasien setelah menjalani perawatan yang dialami pada malam hari (Wright et al., 2015).

4. Anemia

Faktor berikutnya yang menyebakan fatigue pada pasien kemoterapi adalah anemia. Pada penelitian Di Marco et al., (2018) mengatakan pasien yang mengalami baik anemia ringan maupun berat secara signifkan dikaitkan dengan penyebab fatigue pada pasien dengan kemoterapi dengan nilai $p=0,001$.

5. Body Mass index (BMI) /Indeks Massa Tubuh

Faktor BMI yang tinggi secara signifikan dapat menyebabkan dan meningkatkan fatigue pada pasien kemoterapi (Limpawattana et al., 2019). BMI yang tinggi berhubungan dengan obesitas yang merupakan faktor risiko utama fatigue. Selain obesitas, menurut penelitian yang dilakukan oleh (Di Marco et al., 2018) penurunan berat badan $<16 \mathrm{~kg}$ dalam 3 bulan selama kemoterapi pada pasien kanker secara signifikan dapat juga menyebabkan fatigue yang parah dengan nilai $\mathrm{p}=0,003$.

6. Komorbiditas

Dalam penelitian (Vardy et al., 2016) mengatakan bahwa komorbiditas merupakan faktor yang mempengaruhi fatigue dimana pada jumlah komorditas yang tinggi memiliki hubungan yang signifikan dengan fatigue yang lebih parah. Selain itu, faktor komorditas ditemukan secara signifikan baik terhadap 
fatigue ringan sampai yang berat dengan nilai $p<0,001$ yang disebabkan terbanyak karna penyakit kardiovaskuler.

7. Tingkat fatigue awal sebelum tindakan

Tingkat fatigue diawal sebelum menerima tindakan pengobatan secara signifikan dapat menyebabkan dan memperparah fatigue pada pasien saat menjalani dan setelah kemoterapi (Araújo et al., 2017). Selain itu, serupa dengan penelitian yangdilakukan olehReinertsen et al., (2017) yang menemukan bahwa pada pasien wanita yang menjalani kemoterapi memiliki tingkat fatigue yang lebih tinggi dibandingkan padapasien yang tidak merasakan fatigue sebelum kemoterapi.

Perbedaan usia dari kedua artikel yang diulas sebagai faktor pemicu fatigue dimana usia muda sebagai faktor penyebabnya (Bischel et al., 2016). Hal ini didukung dengan penelitian yang mengatakan tingkat fatigue lebih rendah dialami pada pada pasien yang lebih tua (Ritchie et al., 2014). Namun hal tersebut dapat disebabkan karna pasien yang dewasa muda memiliki tanggung jawab yang berbeda dalam perawatan terkait yang berkontribusi dalam meningkatakan tingkat fatigue dibandingkan pasien dewasa yang lebih tua yang memiliki waktu istirahat pada malam hari yang lebih banyak sehingga berkontribusi dalam penurunan fatigue yang dirasakan (Bischel et al., 2016). Berbeda dengan penelitian yang dilakukan oleh Limpawattana et al.,(2019) bahwa pasien dengan kemoterapi pada usia yang lebih tua menunjukkan resiko tinggi mengalami fatigue diakibatkan mengalami berbagai gangguan 
status fungsional yang lebih parah. Hal ini dibenarkan dalam penelitian sebelumnya yang menyatakan adanya hubungan yang positif antara status fungsional yang buruk dan berbagai tingkat masalah gangguan penyakit yang cukup tinggi pada usia yang lebih tua yang akan memicu fatigue yang lebih parah (Miaskowski et al., 2014; Dhruva et al., 2013; Berger, Gerber, \& Mayer, 2012). Selain itu, dilaporka usia > 65 tahun melaporkan lebih banyak mengalami fatigue (Di Marco et al., 2018). Oleh karena itu, gejala fatigue lazim dialami pada semua kelompok usia baik pada orang dewasa yang lebih tua dan lebih muda dan belum tentu mengalami gejala yang berbeda serta gangguan ini mungkin tidak secara langsung terkait dengan tingkat keparahan.(Soltow, Given, \& Given, 2010). Namun usia merupakan faktor resiko yang tidak dapat dimodifikasi untuk mencegah masalah ini (Wright et al., 2015b)

Pada kedua ulasan ditemukan Ras berkulit putih merupakan faktor penyebab fatigue. Namun pada perbedaan ras baik berkulit putih maupun hitam pada penelitian sebelumnya melaporkan tidak ada perbedaan terhadap tingkat fatigue yang dialami pada pasien yang menerima kemoterapi (Berger, Lockhart, \& Agrawal, 2009; Byar, Berger, Bakken, \& Cetak, 2006) bahkan pada penelitian Wang et al., (2014) fatigue yang lebih parah dialami pada pasien kulit hitam. Oleh karena itu representasi ras minoritas yang kurang dalam setiap penemuan dalam tiap studi dapat mungkin membatasi kekuatan untuk mendeteksi perbedaan keparahan fatigue pada populasi pasien ini berdasarkan ras. 
Faktor tekanan psikologi seperti stress, kecemasan dan depresi yang ditemukan dalam ulusan ini juga didukung dalam penelitian (Byar et al., 2006) dimana fatigue berkorelasi dengan psikologis seperti kecemasan dan depresi tertinggi pada awal dan selama pengobatan kemoterapi dan secara konsisten mengikuti perawatan. Hal ini dapat terjadi akibat masalah emosional dapat mempengaruhi peningkatan tekanan darah dan kontrraksi jantung yang mengakibatkan penurunan oksigen dan sekresi insulin sehingga terjadi penurunan energi yang menyebabkan fatigue (Danismaya, 2008). Hal ini dibuktikan pada penelitian (Bischel et al., 2016) penurunan energi pada pasien yang menjalani kemoterapi memberikan skor keparahan terhadap gejala fatigue. Sehingga bagi pasien yang mengalami tekanan psikologi seperti stress, cemas dan depresi yang memiliki tingkat fatigue selama pengobatan harus mendapatkan perhatian. Dalam sebuah studi uji coba menunjukkan pengurangan stres berbasis kesadaran dalam meningkatkan gejala psikologis dan kualitas hidup yang terkait dengan fatigue dalam menjalani pengobatan (Lengacher et al., 2016). Tetapi berbeda dengan penelitian (Di Marco et al., 2018) yang menemukan depresi tidak menunjukkan hubungan yang signifikan dengan fatigue.

Dalam penelitian Di Marco et al., (2018)anemia secara signifikan menyebabkan fatigue. Didukung dengan penelitian Sobecks \& Theil, (2017) yang menemukan salah satu faktor yang menyebabkan fatigue yaitu anemia. Hal ini dapat disebabkan efek dari kemoterapi dapat memberikan pengaruh pada fungsi siklus sel 
normal dalam penyerapan nutrisi untuk sel sehingga mengakibatkan gangguan pada pembentukan pada sel darah salah satunya untuk menghasilkn sel darah merah yang mengikat haemoglobin dan berperan dalam membawa oksigen (Kamariah, 2018; Hidayat, 2013), kadar hemoglobin yang rendah dikaitkan dengan fatigue yang lebih besar pada pasien kanker (Banipal, Singh, \& Singh, 2017). Jumlah hemoglobin yang lebih rendah pada awal dikaitkan dengan fatigue yang lebih besar, meskipun kadar hemogloin sering dalam kisaran normal (Vardy et al., 2016). Namun berbeda dengan temuan yang menyatakan kadar hamoglobin yang dikaitkan dengan anemia tidak terkait dengan fatigue yang muncul setelah kemoterapi. Hal ini dapat diakibatkan dengan panjang siklus kemoterapi yang diterima dan adanya perbedaan antara individu terkait factor penentu genetik dan epigenetik (Wright et al., 2015b).

Massa tinggi lemak atau obesitas adalah faktor lain yang berhubungan dengan BMI yang menunjukkan fatigue, namun ini bukan merupakan faktor independen yang telah disesuaikn sebagai faktor BMI. Data ini menunjukkan bahwa obesitas berkaitan dengan fatigue tetapi tidak hanya pada massa tinggi lemak. Dimana untuk setiap peningkatan BMI $1 \mathrm{mg} / \mathrm{m} 2$ merupakan faktor resiko yang mengakibatkan fatigue meningkat 1,3 kali. Hasil ini didukung oleh banyak hasil penelitian yang memberikan data tentang orang dewasa yang tinggal di komunitas (Sheehan, O'Connell, Cunningham, Crosby, \& Kenny, 2013). Namun adanya faktor atau konsekuensi lain yang mengarah ke ketidakmampuan untuk 
menyesuaikan diri dengan stresor seperti status gizi, aktivitas fisik, peradangan yang dapat menjadi penyebab terjadinya obesitas atau BMI yang meningkat (Limpawattana et al., 2019). Selain itu penurunan berat badan juga dapat menjadi faktor penyebab (Di Marco et al., 2018). Hal ini sering dikaitkan dengan cachexia neoplastic. Sejalan dengan penelitian yaang dinilai oleh penulis lain, mengatakan penurunan berat badan sangat penting dianggap sebagai faktor yang mempengaruhi penyebab fatiguepada banyak pasien (Anandavadivelan, Wikman, Johar, \& Lagergren, 2018).

Komorditas merupakan salah satu penyebab fatigue. Dengan jumlah komorbiditas pasien kemoterapi yang lebih tinggi, seperti penyakit jantung, paru-paru, penyakit darah, ginjal (Bischel et al., 2016). Hal ini dibuktikan bahwa salah sat faktor yang kontribusi potensial terkait dengan fatigue pada pasien kanker termasuk komorbiditas medis (Bower \& E, 2014). Hal ini dapat disebabkan pasien kanker dengan kemoterapi memiliki dampak metastasi yang lebih tinggi sehingga dapat mengakibatkan munculnya berbagai penyakit lainnya yang dapat memicu fatigue yang lebih parah (Vardy et al., 2016). Namun berbeda dari hasil temuan Di Marco et al., (2018) bahwa fatigue dapat terjadi akibat dampak dari kemoterapi dan kankernya bukan akibat dari komordibitas lain karena fatigue yang ditemukan lebih tinggi terjadi pada pasien yang tidak memiliki penyakit penyerta dibandingkan pada pasien yang memiliki penyakit lain. Namun menempatkan bukti lain yang paling berkorelasi dengan fatigue diantara komorbiditas yang dilaporkan 
oleh pasien yaitu penyakit kardiovaskular dan muskuloskletal.

Fatigue sebelum kemoterapi dapat memicu serta memperparah keadaan pasien saat bahkan setelah kemoterapi. Dimana fatigue yang terjadi pada pra perlakukan pemberian pengobatan kemoterapi berhubungan dengan adanya tanda inflamasi yang terjadi sehingga secara signifikan cenderung menyebabkan fatigue setelah kemoterapi (Andrykowski, Donovan, Laronga, \& Jacobsen, 2010). Oleh karena itu, inflamasi sebagai predisposisi fatigue sebelum tindakan kemotrapi dapat menjadi penanganan awal sebelum tindakan kemoterapi karena hal ini dapat memicu pasien rentang mengalami fatigue dan memperparahsetelah mendapatkan perawatan.

Studi litatur kami menunjukkan fatigue pada pasien
kemoterapi merupakan gejala yang dapat dipengaruhi oleh banyak faktor seperti usia, ras, tekanan psikologis, anemia, body mass index (BMI) /indeks massa tubuh, komorbiditas, tingkat fatigue awal sebelum kemoterapi. Oleh karena itu, faktor tersebut menjadi perhatian penting untuk dideteksi secara dini baik oleh pasien, keluarga maupun petugas kesehatan sehingga dapat dimodifikasi dalam memberikan intervensi yang tepat untuk mencegah terjadinya fatigueyang memiliki dampak terhadap penurunan kualitas hidup pasien bahkan kematian bagi pasien.

\section{DAFTAR PUSTAKA}

Anandavadivelan, P., Wikman, A., Johar, A., \& Lagergren, P. (2018). Impact of weight loss and eating difficulties on health-related quality of life up to 10 years after oesophagectomy for cancer. British Journal of Surgery, 105(4), 410-418. https://doi.org/10.1002/bjs.10686 
Andrykowski, M. A., Donovan, K. A., Laronga, C., \& Jacobsen, P. B. (2010). Prevalence, predictors, and characteristics of off-treatment fatigue in breast cancer survivors. Cancer, 116(24), 5740-5748. https://doi.org/10.1002/cncr.25294

Araújo, J. K. L., Giglio, A. del, Munhoz, B. A., Fonseca, F. L. A., Cruz, F. M., \& Giglio, A. del. (2017). Chemotherapy-Induced Fatigue Correlates With Higher Fatigue Scores Before Treatment. American Journal of Hospice and Palliative Medicine, 34(5), 404-411. https://doi.org/10.1177/1049909116629134

Banipal, R. P. S., Singh, H., \& Singh, B. (2017). Assessment of Cancerrelated Fatigue among Cancer Patients Receiving Various Therapies: A Cross-sectional Observational Study. Indian Journal of Palliative Care, 23(4), 317-320. https://doi.org/10.4103/IJPC.IJPC

Berger, A. M., Gerber, L. H., \& Mayer, D. K. (2012). Cancer-related fatigue: Implications for breast cancer survivors. Cancer, 118(SUPPL.8), 2261-2269. https://doi.org/10.1002/cncr.27475

Berger, A. M., Lockhart, K., \& Agrawal, S. (2009). Variability of patterns of fatigue and quality of life over time based on different breast cancer adjuvant chemotherapy regimens. Oncology Nursing Forum, 36(5), 563-570. https://doi.org/10.1188/09.ONF.563-570

Bischel, L. E., Ritchie, C., Kober, K. M., Paul, S. M., Cooper, B. A., Chen, L. M., ... Miaskowski, C. (2016). Age differences in fatigue, decrements in energy, and sleep disturbance in oncology patients receiving chemotherapy. European Journal of Oncology Nursing, 23, 115-123. https://doi.org/10.1016/j.ejon.2016.07.002

Bower, \& E, J. (2014). Cancer-related fatigue: Mechanisms, risk factors, and treatments. Physiology \& Behavior, 11(10), 597-609. https://doi.org/10.1038/nrclinonc.2014.127

Byar, K. L., Berger, A. M., Bakken, S. L., \& Cetak, M. A. (2006). Impact of adjuvant breast cancer chemotherapy on fatigue, other symptoms, and quality of life. Oncology Nursing Forum, 33(1), 18-26. https://doi.org/10.1188/06.ONF.E18-E26 
Charalambous, A., \& Kouta, C. (2016). Cancer Related Fatigue and Quality of Life in Patients with Advanced Prostate Cancer Undergoing Chemotherapy. BioMed Research International, 2016, 11. https://doi.org/10.1155/2016/3989286

Cleeland, C. S., Zhao, F., Chang, V. T., Sloan, J. A., O'Mara, A. M., Gilman, P. B., ... Fisch, M. J. (2013). The symptom burden of cancer: Evidence for a core set of cancer-related and treatment-related symptoms from the Eastern Cooperative Oncology Group Symptom Outcomes and Practice Patterns study. Cancer, 119(24), 4333-4340. https://doi.org/10.1002/cncr.28376

Danismaya, I. (2008). Pengaruh tehnik relaksasi yoga terhadap fatigue penderita kanker pasca kemoterapi.

Dhruva, A., Aouizerat, B. E., Cooper, B., Paul, S. M., Dodd, M., West, C., ... Miaskowski, C. (2013). Differences in morning and evening fatigue in oncology patients and their family caregivers. European Journal of Oncology Nursing, 17(6), 841-848. https://doi.org/10.1016/j.ejon.2013.06.002

Di Marco, M., Rubbi, I., Baldi, A., Di Lorenzo, R., Magnani, D., Cremonini, V., ... Ferri, P. (2018). Evaluation of fatigue in patients with pancreatic cancer receiving chemotherapy treatment: A crosssectional observational study. Acta Biomedica, 89(4), 18-27. https://doi.org/10.23750/abm.v89i4-S.7063

Ferlay, J., Colombet, M., Soerjomataram, I., Mathers, C., Parkin, D. M., Piñeros, M., ... Bray, F. (2019). Estimating the global cancer incidence and mortality in 2018: GLOBOCAN sources and methods. International Journal of Cancer, 144(8), 1941-1953. https://doi.org/10.1002/ijc.31937

Galizia, D., Milani, A., Geuna, E., Martinello, R., Cagnazzo, C., Foresto, M., ... Montemurro, F. (2018). Self-evaluation of duration of adjuvant chemotherapy side effects in breast cancer patients: A prospective study. Cancer Medicine, 7(9), 4339-4344. https://doi.org/10.1002/cam4.1687

Hidayat, Y. M. (2013). Prinsip Dasar Kemoterapi. In A. D. Anwar (Ed.), Bandung Controversies and Consensus in Obstetrics \& Gycenology. 
Jakarta.

Kamariah, N. (2018). Pengaruh Latihan Fisik Minimal Terhadap Fatigue Pasien Kanker Serviks di RSUP Haji Adam Malik Medan SKRIPSI.

Kementerian Kesehatan RI. (2019). Hari Kanker Sedunia 2019. Retrieved from https://www.kemkes.go.id/article/view/19020100003/harikanker-sedunia-2019.html

Kementrian Kesehatan RI. (2018). Laporan Nasional Riskesdas 2018. Indonesia.

Kim, H. S., Oh, E. G., Lee, H., Kim, S. H., \& Kim, H. K. (2015). Predictors of symptom experience in Korean patients with cancer undergoing chemotherapy. European Journal of Oncology Nursing, 19(6), 644653. https://doi.org/10.1016/j.ejon.2015.04.003

Lengacher, C. A., Reich, R. R., Paterson, C. L., Ramesar, S., Park, J. Y., Alinat, C., ... Kip, K. E. (2016). Examination of broad symptom improvement resulting from mindfulness-based stress reduction in breast cancer survivors: A randomized controlled trial. Journal of Clinical Oncology, 34(24), 2827-2834. https://doi.org/10.1200/JCO.2015.65.7874

Limpawattana, P., Wirasorn, K., Sookprasert, A., Sawanyawisuth, K., Titapun, A., Luvira, V., ... indaprasirt, J. (2019). Frailty syndrome in biliary tract cancer patients: Prevalence and associated factors. Asian Pacific Journal of Cancer Prevention, 20(5), 1497-1501. https://doi.org/10.31557/APJCP.2019.20.5.1497

Lopez, V., Williams, P., \& Larkin, D. (2015). Treatment-related symptom severity and occurrences among oncology adults in Australia. 2(3). https://doi.org/10.4103/2347-5625.160973

Miaskowski, C., Cooper, B. A., Melisko, M., Chen, L. M., Mastick, J., West, C., ... Aouizerat, B. E. (2014). Disease and treatment characteristics do not predict symptom occurrence profiles in oncology outpatients receiving chemotherapy. Cancer, 120(15), 2371-2378. https://doi.org/10.1002/cncr.28699 
National Cancer Institute. (2018). Chemotherapy and You (p. 60). p. 60. Retrieved from http://www.cancer.gov/cancertopics/coping/chemotherapy-andyou

O'Connel, K. (2015). What Causes Fatigue? Retrieved from https://www.healthline.com/symptom/fatigue

Reinertsen, K. V., Engebraaten, O., Loge, J. H., Cvancarova, M., Naume, B., Wist, E., ... Kiserud, C. E. (2017). Fatigue During and After Breast Cancer Therapy-A Prospective Study. Journal of Pain and Symptom Management, 53(3), 551-560. https://doi.org/10.1016/j.jpainsymman.2016.09.011

Ritchie, C., Dunn, L. B., Paul, S. M., Cooper, B. A., Skerman, H., Merriman, J. D., ... Miaskowski, C. (2014). Differences in the symptom experience of older oncology outpatients. Journal of Pain and Symptom Management, 47(4), 697-709. https://doi.org/10.1016/j.jpainsymman.2013.05.017

Robison, J. G., \& Smith, C. L. (2016). Therapeutic Massage During Chemotherapy and/or Biotherapy Infusions:20(2).

Schmidt, M. E., Wiskemann, J., Armbrust, P., Schneeweiss, A., Ulrich, C. M., \& Steindorf, K. (2014). breast cancer patients undergoing adjuvant chemotherapy: A randomized controlled trial. 00. https://doi.org/10.1002/ijc.29383

Schmidt, M. E., Wiskemann, J., Ulrich, C. M., \& Steindorf, K. (2014). Efek latihan ketahanan pada kelelahan dan kualitas hidup pada pasien kanker payudara yang menjalani kemoterapi adjuvan: Sebuah uji coba terkontrol secara acak. 00.

Sheehan, K. J., O'Connell, M. D. L., Cunningham, C., Crosby, L., \& Kenny, R. A. (2013). The relationship between increased body mass index and frailty on falls in community dwelling older adults. BMC Geriatrics, 13(1). https://doi.org/10.1186/1471-2318-13-132

Sobecks, R. M., \& Theil, K. (2017). Cleveland Clinic. Retrieved from http://www.clevelandclinicmeded.com/medicalpubs/diseasemanag ement/hematology-oncology/chronic-leukemias/ 
Soltow, D., Given, B. A., \& Given, C. W. (2010). Relationship Between Age and Symptoms of Pain and Fatigue in Adults Undergoing Treatment for Cancer. 33(4), 296-303.

Vardy, J. L., Dhillon, H. M., Pond, G. R., Renton, C., Dodd, A., Zhang, H., ... Tannock, I. F. (2016). Fatigue in people with localized colorectal cancer who do and do not receive chemotherapy: A longitudinal prospective study. Annals of Oncology, 27(9), 1761-1767. https://doi.org/10.1093/annonc/mdw252

Wang, X. S., Zhao, F., Fisch, M. J., O'Mara, A. M., Cella, D., Mendoza, T. R., \& Cleeland, C. S. (2014). Prevalence and characteristics of moderate to severe fatigue: A multicenter study in cancer patients and survivors. Cancer, 120(3), 425-432. https://doi.org/10.1002/cncr.28434

Wright, F., D’Eramo Melkus, G., Hammer, M., Schmidt, B. L., Knobf, M. T., Paul, S. M., ... Miaskowski, C. (2015a). Predictors and trajectories of morning fatigue are distinct from evening fatigue. Journal of Pain and Symptom Management, 50(2), 176-189. https://doi.org/10.1016/j.jpainsymman.2015.02.016

Wright, F., D’Eramo Melkus, G., Hammer, M., Schmidt, B. L., Knobf, M. T., Paul, S. M., ... Miaskowski, C. (2015b). Trajectories of evening fatigue in oncology outpatients receiving chemotherapy. Journal of Pain and Symptom Management, 50(2), 163-175. https://doi.org/10.1016/j.jpainsymman.2015.02.015

Yagli, N. V., \& Ulger, O. (2015). Complementary Therapies in Clinical Practice The effects of yoga on the quality of life and depression in elderly breast cancer patients. Complementary Therapies in Clinical Practice, 21(1), 7-10. https://doi.org/10.1016/j.ctcp.2015.01.002

Yeo, T. P., \& Cannaday, S. (2015). Cancer-related fatigue: impact on patient quality of life and management approaches. Nursing: Research and Reviews, 65. https://doi.org/10.2147/NRR.S41957 